\title{
Correction to: Genomic analysis of Leptospira interrogans serovar Paidjan and Dadas isolates from carrier dogs and comparative genomic analysis to detect genes under positive selection
}

\author{
Alongkorn Kurilung ${ }^{1}$, Chantisa Keeratipusana ${ }^{2}$, Prapat Suriyaphol ${ }^{2}$, David J. Hampson ${ }^{3}$ and Nuvee Prapasarakul ${ }^{1,4^{*}}$ (1)
}

\section{Correction to: BMC Genomics (2019) 20:168 https://doi.org/10.1186/s12864-019-5562-z}

Following the publication of this article [1], the authors noted an error in the caption of Fig. 4. The caption was published incorrectly as:

Figure 4 The distribution and conservation of 33 representative confirmed virulence genes in pathogenic, intermediate and non-pathogenic Leptospira species. Genes encoding for outer membrane protein (loa22), flagella motor switch protein $(f l i Y)$, and hemolysins $B$ and $\mathrm{C}(\mathrm{tlyB}$ and $t l y C)$ were conserved in all 24 Leptospira strains. Genes encoding was conserved only in pathogenic Leptospira strains. Strains CUDO5 and CUDO8 contained all of the 33 virulence genes

The correct figure and caption is reproduced in this Correction article:

The original article has been corrected.

\section{Author details}

${ }^{1}$ Department of Microbiology, Faculty of Veterinary Science, Chulalongkorn University, Bangkok, Thailand. ${ }^{2}$ Bioinformatics and Data Management for Research Unit, Office for Research and Development, Faculty of Medicine Siriraj Hospital, Mahidol University, Bangkok, Thailand. ${ }^{3}$ Department of Infectious Diseases and Public Health, College of Veterinary Medicine and Life Sciences, City University of Hong Kong, Kowloon Tong, Hong Kong SAR. ${ }^{4}$ Diagnosis and Monitoring of Animal Pathogens Research Unit, Department of Microbiology, Faculty of Veterinary Science, Chulalongkorn University, Bangkok, Thailand.
Received: 14 March 2019 Accepted: 14 March 2019

Published online: 28 March 2019

\section{Reference}

1. Kurilung A, et al. Genomic analysis of Leptospira interrogans serovar Paidjan and Dadas isolates from carrier dogs and comparative genomic analysis to detect genes under positive selection. BMC Genomics. 2019;20(168). https:// doi.org/10.1186/s12864-019-5562-z.

\footnotetext{
* Correspondence: nuvee.p@chula.ac.th

${ }^{1}$ Department of Microbiology, Faculty of Veterinary Science, Chulalongkorn University, Bangkok, Thailand

${ }^{4}$ Diagnosis and Monitoring of Animal Pathogens Research Unit, Department of Microbiology, Faculty of Veterinary Science, Chulalongkorn University, Bangkok, Thailand

Full list of author information is available at the end of the article
}

(c) The Author(s). 2019 Open Access This article is distributed under the terms of the Creative Commons Attribution 4.0 International License (http://creativecommons.org/licenses/by/4.0/), which permits unrestricted use, distribution, and reproduction in any medium, provided you give appropriate credit to the original author(s) and the source, provide a link to the Creative Commons license, and indicate if changes were made. The Creative Commons Public Domain Dedication waiver (http://creativecommons.org/publicdomain/zero/1.0/) applies to the data made available in this article, unless otherwise stated. 


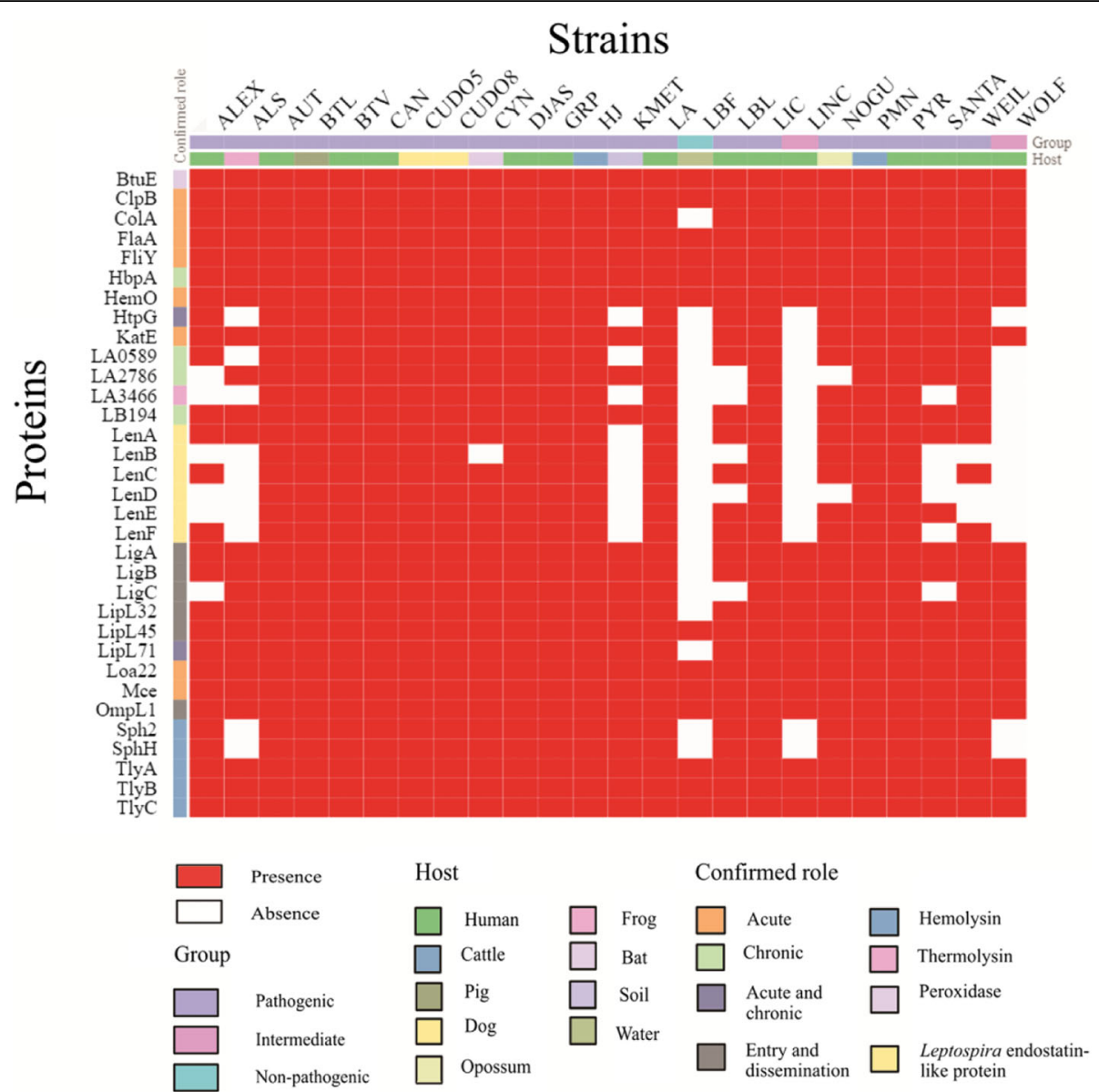

Fig. 4 The distribution and conservation of 33 representative confirmed virulence genes in pathogenic, intermediate and non-pathogenic Leptospira species. Genes encoding for outer membrane protein (loa22), flagella motor switch protein (fliy), and hemolysins B and C (tlyB and tlyC) were conserved in all 24 Leptospira strains. Gene involved with chronic infection (Ib194) was conserved only in pathogenic Leptospira strains. Strains CUDO5 and CUDO8 contained all of the 33 virulence genes 